chapters, giving a sense of uniformity throughout the book.

The book is incomplete as a text-book on food science; but it does cover a large and a very important part of the subject. This will be realized from its contents, which consist of a well-balanced and thoughtful introduction followed by successive chapters on economics, supply and distribution of foods in the United Kingdom; the principal foodstuffs-meat, fish, eggs, fresh fruit and vegetables, potatoes and cereals ; the basic constituents of foods - proteins, mucopolysaccharides and mucoproteins, carbohydrates and fats; some aspects of quality in foods; the micro-organisms; chemical mechanisms of spoilage ; and the principles of food preservation. No chapter of the book gives a full account of the subject discussed-indeed, this would necessitate a book on each-but what is done is to give information and explanation which should advance the intelligent application of science to the study and the industry of food.

Though the standard of information and description is in general a high one which can be properly understood and appreciated only by those who have considerable scientific knowledge and some experience of food science, there are included matters such as data and statements on well-known technical procedures which, though perhaps essentials of the course of lectures, are not so valuable in a book of this standard. This is noticeable especially in Chapter 7 on "The Principles of Food Preservation", which consists largely of such matter, and markedly so in the section on sugar preserves, no doubt because sugars are relatively simple and well-understood constituents of food and because, too, new work in this subject is more associated with their analytical separation and measurement-which matters do not come within the purview of this book. One point of criticism is that the reader may feel, as I certainly did, that in some of the sections there are too many references quoted, many of which seem unnecessary.

E. B. HuGHes

\section{VESALIUS ON THE BRAIN}

Vesalius on the Human Brain

Introduction, Translation of Text, Translation of Descriptions of Figures, Notes to the Translations, Figures. By Charles Singer. (Publications of the Wellcome Historical Medical Museum, New Series, No. 4.) Pp. xxvi+152. (London, New York and Toronto: Oxford University Press, 1952.) 21s. net.

Trit $\mathrm{HE}$ writer of this review is conscious that its title may be perverted into a double entendre, and indeed it does recall the following incident. When Harvey Cushing was staying with Osler at his Oxford house, familiarly known as "The Open Arms", a visitor who called to see them was told by Lady Osler that the two Vesalius lunatics were in the Bodleian Library. To these two romantic disciples of Vesalius may now be added a third, in the formidable person of Dr. Charles Singer.

A detailed annotated translation into English or other modern language of the whole of the "Fabrica" of Vesalius is long overdue, although it could not fail to be a profitable enterprise, and its paramount importance to the historian of seience is only too evident. The difficulty of the undertaking, however, amply explains the delay. In fact, it seems as if nothing short of a panel of scholars would suffice for the task. Vesalius's Latin is often bewildering, and his meaning may be so obscure as to call for very free and imaginative translation, nor does he always acknowledge his debts to predecessors. Hence the translators must be able to command a knowledge of the history of anatomy as it came down to Vesalius from the time of the Greeks. A few of the figures are also incomprehensible, and even so learned and experienced an interpreter as Dr. Singer is constrained to give them up. Some translation has already been attempted. We have a beautifully printed French version by Verschaffelt of the first six chapters (Haarlem, 1924), English translations of the last chapter and the preface by Farrington (1931-32), German and three Dutch translations of the Epitome (1543, 1569, 1583-86, 1647), English translation by Saunders and O'Malley of Lib. I, Chap. 39 (1946), English translation of the captions of the figures by Saunders and O'Malley (1950), English translation of the Epitome by Lind and Asling (1949), and minor fragments by Lambert and Hotchkiss $(1935,1942)$. These, however, touch no more than the fringe of the task, and most of them lack the indispensable commentary.

Dr. Singer's translation is based on the first edition of the "Fabrica"; but the second edition has been drawn upon for corrections and additions. These are the only editions for which Vesalius himself was responsible. If we may assume that the high standard of Dr. Singer's edition will be maintained in the complete work, we shall have a modern version of the "Fabrica" of the utmost value, since it could no longer be excusable to consult the illustrations without studying the text.

The present monograph opens with an introduction, in which the author extols the "Fabrica" as one of the great achievements of the human spirit. Its beautiful figures, he says, are Vesalius's most permanent contribution to science, and they establish exact graphic treatment as an essential adjunct of biological research, and as the causa causans of the organic sciences. He, however, emphasizes that Vesalius's anatomy is by no means all human. For example, the vascular system is derived from various animals, and may be roughly described as the venous system of ungulates and the arterial system of monkeys. The Introduction includes a brief analysis of the seven books of the "Fabrica", its 'tiresome" Ciceronian literary style, Vesalius as a physiological Galenist, and Vesalius as a discoverer and his debts to his predecessors, especially in regard to his work on the brain. The excellent diagram of Galen's physiological system on p. xix fails to show, what Dr. Singer, of course, knows full well, that the pulmonary artery and precaval vein are afferent and efferent to the heart according to Galen, and that the anterior projection of the "rete mirabile" is the modern chorioid plexus of the lateral ventricle.

The Introduction is followed by the English translation of Chapters 1-12 and 18 of Book 7, which deal with the brain and its dissection, after which come Dr. Singer's instructive notes and comments. Finally all Vesalius's figures of the brain are reproduced and their captions translated, to which are added some pre-Vesalian brain figures by Laurentius (1518), Berengarius (1523), Dryander (1536) and Stephanus (published 1545).

Dr. Singer is to be warmly congratulated on this highly important addition to the Vesalian corpus.

F. J. COLE 